\title{
NOTES ON THISMIA CLANDESTINA (THISMIACEAE), A LITTLE-KNOWN MYCOHETEROTROPHIC SPECIES
}

\author{
Sahut Chantanaorrapint ${ }^{1}$, Niyana Tetsana $\&$ Kitichate SRidith
}

\begin{abstract}
Thismia clandestina (Blume) Miq., a rare mycoheterotrophic species previously known only from Indonesia, was newly discovered in tropical lowland forest in southern Thailand. A description, line drawings and photographs are provided, and its diagnostic characters and geographical distribution are briefly discussed.
\end{abstract}

Key words: achlorophylly, distribution, Indonesia, mycoheterotrophy, Thailand

Sahut Chantanaorrapint \& Kitichate Sridith, PSU-Herbarium, Department of Biology, Faculty of Science, Prince of Songkla University, Hat Yai, Songkhla, 90112,Thailand; e-mail: chantanaorrapint@gmail.com

Niyana Tetsana, Forest Herbarium, Department of National Parks, Wildlife and Plant Conservation, Chatuchak, Bangkok 10900, Thailand

\section{INTRODUCTION}

The genus Thismia Griff. is the largest genus of Thismiaceae, with about 55 species currently accepted (e.g., Hroneš 2014; Hunt et al. 2014; Merckx \& Smets 2014; Mar \& Saunders 2015; Chantanaorrapint \& Sridith 2015). The genus is distributed mainly in tropical regions, with a concentration of species in Southeast Asia (Jonker 1938; Maas et al. 1986; Merckx et al. 2013). Due to their small size with highly reduced vegetative morphology, most Thismia species are easily overlooked in the field and appear to have been collected only once or a few times.

In October 2010 the first author collected a fruiting specimen of an unknown Thismia from Sri Phangnga National Park, southern Thailand. Flowering specimens were subsequently re-collected by the staff of herbarium BKF during botanical surveys in the same national park between 2011 and 2012. After making a careful examination, the unknown collections were determined as T. clandestina (Blume) Miq., which was previously known only from West Java, Indonesia. The following description and illustration are based on the recent specimens from Thailand.

\footnotetext{
1 Corresponding author
}

\section{RESULTS AND DISCUSSION}

Thismia clandestina (Blume) Miq. Figs 1 \& 2 F1. Ned. Ind. 3: 616. 1859; Ann. Jard. Bot. Buitenzorg 24: 55, Taf. 8. 1911; Monogr. Burmann.: 252. 1938; Fl. Males. 1(4): 24. 1948.

Basionym: Sarcosiphon clandestinus Blume, Mus. Bot. 1(5): 65, fig. 18. 1850; Notizbl. Bot. Gart. BerlinDahlem 8: 38. 1921. TYPE: INDONESIA. Java, Blume s.n. (HOLOTYPE L).

Plants small, terrestrial, achlorophyllous, mycoheterotrophic herbs. Underground part short, dichotomously branched, forming coralliform, hairy, brownish white clusters. Stems erect, simple, whitish, to $10 \mathrm{~cm}$ tall, $2.5-3 \mathrm{~mm}$ in diam., glabrous. Leaves scale-like, glabrous, appressed, triangular-ovate to lanceolate with acute apex, 3-5 $\times 2-2.5 \mathrm{~mm}$, increasing in size to apex of plant, where they are equivalent to floral bracts. Involucral bracts 3, white, similar to upper leaves. Flowers solitary or paired, opening in succession, pale brown to orange-brown. Perianth actinomorphic with 6 tepals fused to form perianth tube with dome-shaped mitre. Perianth tube urceolate, $9-11 \times 5-8 \mathrm{~mm}$, narrowed just above ovary, widest in upper third, with 12 irregularly dentate 


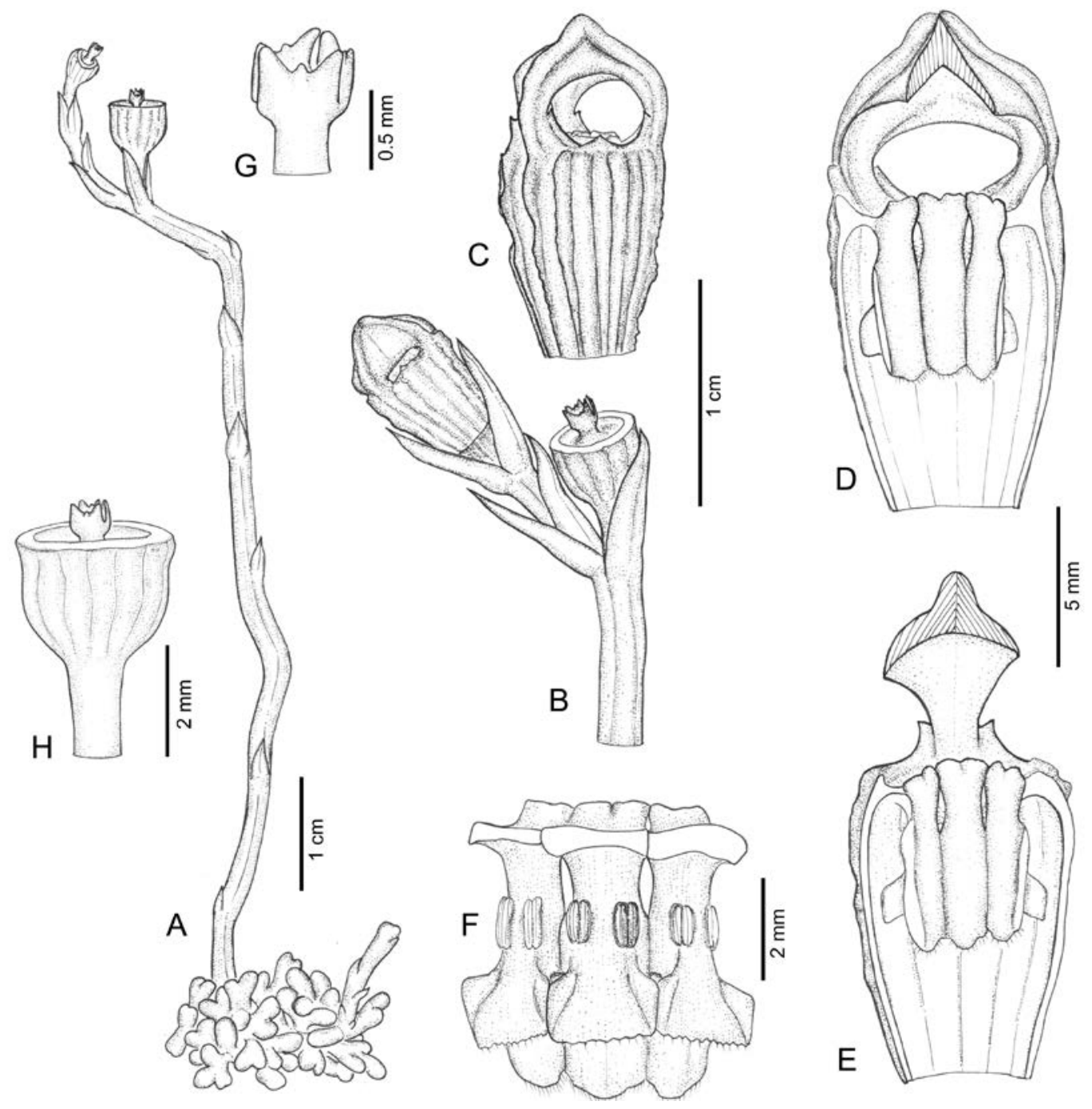

Fig. 1. Thismia clandestina (Blume) Miq. A - habit with immature fruits, B - inflorescence, C - side view of flower, D \& E - longitudinal section of flowers, F - adaxial view of three pendulous stamens, $\mathrm{G}$ - stigma, $\mathrm{H}$ - fruit, immature. Drawn by S. Chantanaorrapint: A \& H from S. Chantanaorrapint 2310 (PSU); B-G from N. Tetsana 401 (BKF).

longitudinal ribs, lacking transverse bars inside. Outer tepals 3, minute or indistinct, broadly triangular. Inner tepals 3, connate to form domeshaped mitre with 3 lateral apertures $3.5-4.5 \mathrm{~mm}$ in diam. Annulus prominent, divided into 6 bilobed flanges $0.50-0.65 \mathrm{~mm}$ high. Stamens 6, pendulous from inner margin of perianth annulus; filaments short, free, ribbon-shaped, hairy at margin; stamens apically connate, forming anther tube around style, ca $5 \mathrm{~mm}$ long; anthers with 4 thecae (abaxial, dehiscing toward inner surface of perianth tube), ca $0.8-1.0 \mathrm{~mm}$ long; nectariferous gland present towards apex on the line of fusion between each connective; connective of stamens broad, forming skirt-like appendage; apex of stamens shallowly trilobed to obtuse, hairy. Ovary inferior, cupshaped, ca $2.0 \times 2.5 \mathrm{~mm}$, with papillose longitudinal ridges, unilocular; placentas 3; styles short, 
ca $0.3 \mathrm{~mm}$, with 3 trilobed stigmas $c a 0.5 \mathrm{~mm}$ long (middle lobe smallest). Fruit cup-shaped, ca $3 \mathrm{~mm}$ long, fruit stalk thickened and lengthened after flowering. Seed not seen.

Distribution. Indonesia (Java), new to Thailand.

Habitat AND ECOLOGY. In Thailand, Thismia clandestina was found growing with other mycotrophic plants such as Epirixanthes sp., Gastrodia phangngaensis Suddee et al., Thismia javanica J. J. Sm. and T. nigricans Chantanaorr. \& Sridith, amongst leaf litter, under shade in lowland evergreen forest, ca $50 \mathrm{~m}$ above sea level. Flowering and fruiting during the rainy season from August to November.

CONSERVATION STATUS. The IUCN (Anonymous 2001) category for $T$. clandestina should be treated at the moment as data deficient (DD). Because of its small size and ephemeral character, it could eas- ily be overlooked in general botanical explorations. It is difficult to further clarify its IUCN status until further surveys of suitable habitat are undertaken.

Specimens examined: THAILAND. Phang Nga, Kura Buri, Bang Wan, Sri Phangnga National Park, 7 Oct. 2010, S. Chantanaorrapint 2310 (PSU), 13 Aug. 2011, N. Tetsana 401 (BKF); ca $200 \mathrm{~m}$ to Ton Deng Waterfall, 54 m, 14 Nov. 2012, V. Chamchumroon et al. $5602 B$ (BKF).

TAXONOMIC NOTES. This species was originally described from Java as Sarcosiphon clandestinus Blume (Blume 1850) based on a fruiting specimen, and subsequently transferred to Thismia by Miquel (1859). Later, Smith (1911) described and illustrated details of flower morphology based on Bernard's collections. The species is characterized by its coralliform underground part, pale brown to orange-brown flowers, mitriform inner tepals with an acute apex, the filament of stamens being hairy at the margin and the apex of the stamens
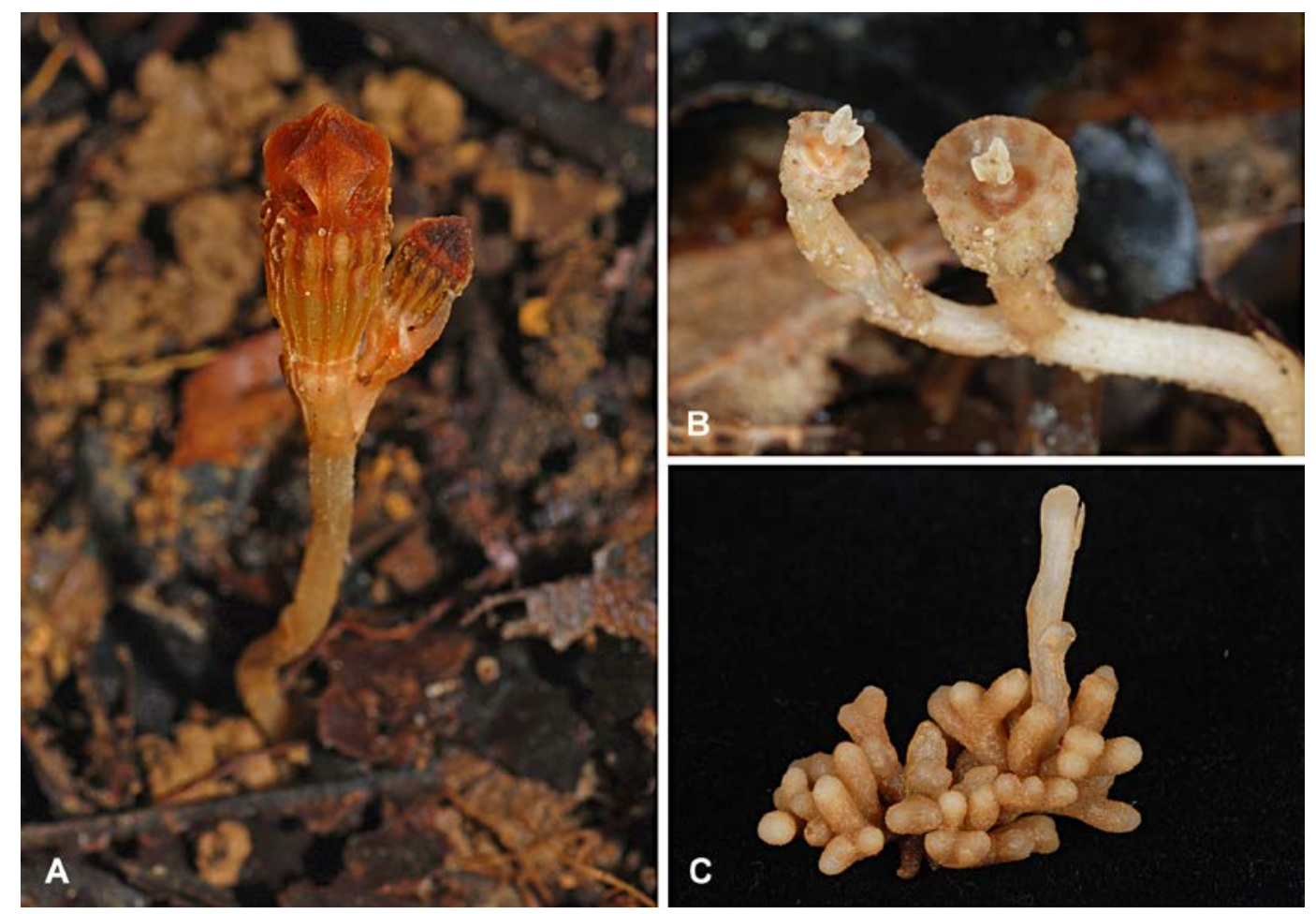

Fig. 2. Thismia clandestina (Blume) Miq. A - habit, B - fruits, C - underground part. Photo N. Tetsana (A) and S. Chantanaorrapint $(\mathrm{B}-\mathrm{C})$. 
trilobed (the middle lobe longest). Interestingly, the stigmas of Bernard's collections as illustrated by Smith (1911) seem to be 3-bilobed, while they are 3-trilobed with the mid-lobe smallest in the material from Thailand. This minor difference may be due to the resolution of Smith's microscope. Jonker (1948) noted that T. clandestina had greenish gray flowers, but the Thai plants are similar to Smith's description in having pale brown to orange-brown flowers. Thismia clandestina closely resembles T. episcopalis (Becc.) F. Muell., an endemic species from Borneo (Jonker, 1938, 1948), in having coralliform roots and mitriform inner tepals with an acute apex. The latter differs from T. clandestina, however, by the staminal filaments lacking marginal hairs and the equally 3-lobed stamen apices.

Thismia clandestina was previously known from a few localities in Java, Indonesia (Blume 1850; Smith 1911; Jonker 1938, 1948). The new record in Thailand represents its northernmost locality, and an addition to the knowledge of the distribution range of this species. It may also occur in other areas in the Malaysia Peninsular and southern Thailand with similar environments. The recent discovery of new species and new distributions of Thismia from Thailand (Chantanaorrapint \& Sridith 2007, 2015; Chantanaorrapint 2008, 2012; Chantanaorrapint \& Chantanaorrapint 2009) suggest that Thailand is one of the richest areas for Thismia. More new records of species are expected in unexplored areas, especially in the lower peninsular part of the country.

ACKNOWLEDGMENTS. We thank the Curators and staff of BKF for kindly allowing us to study specimens, and Kevin R. Thiele (Perth) and the anonymous reviewer for their valuable comments on the manuscript. This work was supported by the Thailand Research Fund (no. TRG5780133) and Prince of Songkla University.

\section{REFERENCES}

ANONYmous 2001. IUCN Red list categories: version 3.1. IUCN Species Survival Commission, Gland, Switzerland \& Cambridge, UK.
Blume C. L. 1850. Museum Botanicum Lugduno-Batavum sive stirpium exoticarum, novarum vel minus cognitarum ex vivis aut siccis brevis expositio et descriptio. 1(5). J. O. La Lau, Leiden.

Chantanaorrapint S. 2008. Thismia angustimitra (Thismiaceae), a new species from Thailand. Blumea 53: 524-526.

Chantanaorrapint S. 2012. Thismia filiformis, a new species of Thismiaceae (formerly Burmanniaceae) from Thailand. Kew Bull. 67: 69-73.

Chantanaorrapint S. \& Chantanaorrapint A. 2009. Thismia clavigera (Thismiaceae), a new record for Thailand. Thai Forest Bull., Bot. 37: 27-31.

Chantanaorrapint S. \& SRIDith K. 2007. Thismia alba (Thismiaceae), a new record for Thailand. Thai Forest Bull., Bot. 35: 34-37.

Chantanaorrapint S. \& Sridith K. 2015. A new species of Thismia (Thismiaceae) from Southern Thailand. Phytotaxa (in press).

Hroneš M. 2014. Thismia gigantea, a new combination in Thismia (Thismiaceae). Phytotaxa 172: 55-56.

Hunt C. A., Steenbeeke G. \& Merckx V. S. F. T. 2014. Thismia megalongensis (Thismiaceae), a new species of Thismia from New South Wales. Telopea 16: 165-174.

JONKER F. P. 1938. Monograph of the Burmanniaceae. Meded. Bot. Mus. Herb. Rijks Univ. Utrecht 51: 1-279.

Jonker F. P. 1948. Burmanniaceae. In: C. G. G. J. van STEENIS, (ed), Flora Malesiana. Series 1, Spermatophyta. 4(1): 13-26. Noordhoff-Kolff N. V., Batavia.

MaAs P. J. M., MaAs-van de Kamer H., van Benthem J. H., SNelders C. M. \& RÜBSAMEN T. 1986. Burmanniaceae. Fl. Neotrop. Monogr. 42: 1-189.

MAR S. S. \& SAUnders R. M. K. 2015. Thismia hongkongensis (Thismiaceae): a new mycoheterotrophic species from Hong Kong, China, with observations on floral visitors and seed dispersal. PhytoKeys 46: 21-33.

Merckx V. S. F. T. \& Smets E. F. 2014. Thismia americana, the $101^{\text {st }}$ anniversary of a botanical mystery. Int. J. Pl. Sci. 175: 165-175.

Merckx V. S. F. T., Freudenstein J. V., Kissling J., Christenhusz M. J. M., Stotler R. E., Crandall-Stotler B., Wickett N., Rudall P. J., MaAsvan de Kamer H. \& MaAs P. J. M. 2013. Taxonomy and classification. In: V. S. F. T. Merckx (ed.), Mycoheterotrophy: the biology of plants living on fungi, pp. 19-101. Springer, New York.

MiQuel F. A. W. 1859. Flora van Nederlandsch Indië. 3. Frid. Fleischer, Lipsiae.

Sмiтн J. J. 1911. I. Zur Systematik von Thismia javanica J. J. Sm. Ann. Jard. Bot. Buitenzorg 23: 32-35. 